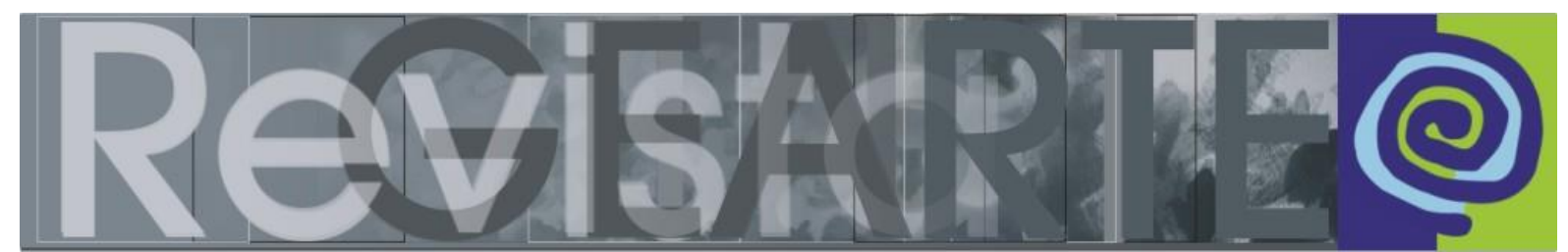

ISSN 2357-9854 | e-ISSN 2596-3198 (online)

\title{
O ensino das Artes Visuais e do Design: o campo da História como estratégia de pesquisa
}

\author{
Lislaine Sirsi Cansi \\ (Universidade Federal de Pelotas - UFPel, Pelotas/RS, Brasil)
}

\begin{abstract}
RESUMO - 0 ensino das Artes Visuais e do Design: o campo da História como estratégia de pesquisa - Esse artigo trata de um estudo teórico que visa aproximar Ensino das Artes Visuais e do Design ancorado a partir de um terceiro campo, o da História, no que diz respeito ao domínio da História da Educação formatado pela abordagem teórico-metodológica da História Cultural. Nesse contexto, foi realizado um levantamento de dados de pesquisas concernentes ao campo do Design produzidas no Programa de Pós-Graduação em Artes Visuais (PPGAV), da Linha Ensino da Arte e Educação Estética, da Universidade Federal de Pelotas (UFPel), com periodicidade entre 2012 e 2018. A partir da análise dos dados investigados foi possível refletir sobre a imbricação que interessa nesse estudo, a relação entre Arte, Ensino e Design, e considerar que no PPGAV/UFPel houve a proposição de um ensino, advindo do Ensino das Artes Visuais, voltado ao âmbito do estético e do sensível para o campo do Design.

PALAVRAS-CHAVE
\end{abstract}

Ensino da Arte. Ensino do Design. Pesquisa histórica. Mestrado em Artes Visuais. Educação do sensível.

ABSTRACT - Teaching Visual Arts and Design: the field of History as a research strategy This article deals with a theoretical study that aims to bring Teaching of the Visual Arts and Design anchored from a third field, that of History, with regard to the domain of the History of Education shaped by the theoretical-methodological approach of Cultural History. In this context, a survey of research data concerning the field of Design produced in the Postgraduate Program in Visual Arts (PPGAV), of Line Art Education and Aesthetic Education, of the Federal University of Pelotas (UFPel), was carried out between 2012 and 2018. From the analysis of the investigated data, it was possible to reflect on the overlap that is of interest in this study, the relationship between Art, Teaching and Design, and consider that in PPGAV / UFPel there was a teaching proposal, arising from the Teaching of Visual Arts, aimed at scope of the aesthetic and the sensitive for the field of Design.

KEYWORDS

Art Education. Design Education. Historical research. Master in Visual Arts. Sensitive education.

\begin{abstract}
RESUMEN - La enseñanza de las Artes Visuales y el Diseño: el campo de la Historia como estrategia de investigación - Este artículo trata de un estudio teórico que tiene como objetivo reunir la Enseñanza de las Artes Visuales y el Diseño anclado desde un tercer campo, el de la Historia, en el que concierne al dominio de la Historia de la Educación conformado por el enfoque teórico-metodológico de la Historia Cultural. En este contexto, se realizó una recopilación de datos de investigaciones sobre el campo del Diseño producidas en el Programa de Posgrado en Artes Visuales (PPGAV), de la Línea Enseñanza de Arte y Educación Estética, de la Universidad Federal de Pelotas (UFPel), con periodicidad entre 2012 y 2018. A partir del análisis de los datos investigados, fue posible reflexionar sobre la superposición que es de interés en este estudio, la relación entre Arte, Enseñanza y Diseño, y considerar que en PPGAV / UFPel había una propuesta de enseñanza, derivada de la Enseñanza de Artes Visuales, centrada en el alcance de lo estético y lo sensible para el campo del diseño.
\end{abstract}

PALABRAS CLAVE

Enseñanza de arte. Educación de diseño. Investigación historica. Maestría en Artes Visuales. Educación sensible. 


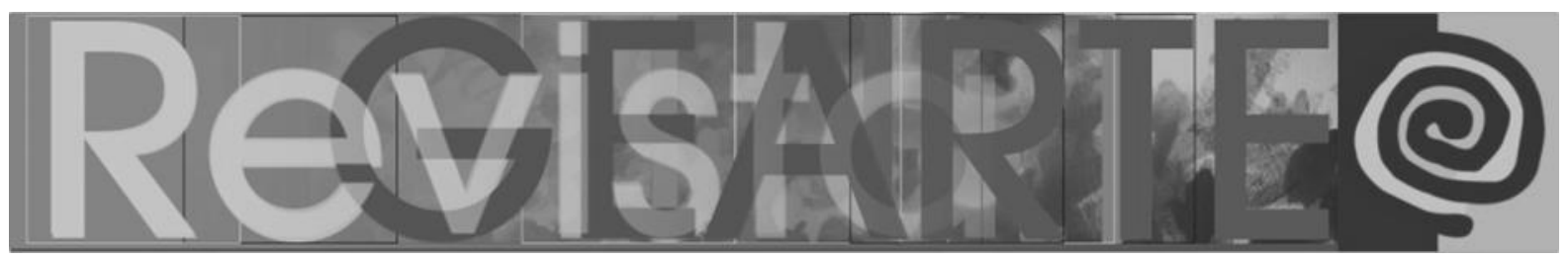

\section{Introdução}

Como é possível reunir pesquisas e reflexões de dois campos, o campo da Arte e o campo do Design, abordando análises de recursos metodológicos ou de aplicação em práticas cotidianas de professores e de pesquisadores nas universidades? No caso desse estudo, o que possibilita é a passagem do tempo. Explico: partindo da questão apresentada, este artigo propõe um estudo teórico conduzido por um terceiro campo, o da História, especificamente sob o domínio da História da Educação pelo viés da História Cultural.

Amparado pelo aporte teórico-metodológico da História Cultural, recorta-se certa realidade e busca-se fazer um estudo tendo como objeto a Universidade Federal de Pelotas (UFPel), restritamente o Programa de Pós-Graduação em Artes Visuais (PPGAV), instituição que produz e que propaga conhecimento, e as dissertações do curso de Mestrado em Artes Visuais pertencentes à Linha 1 Ensino da Arte e Educação Estética ${ }^{1}$, e relacionadas ao campo do Design, como fontes históricas. A questão problematizadora desse estudo aborda de que forma os pesquisadores que percorreram ambos os territórios, próprio ao território de sua formação inicial (Design) ou em sua formação no Programa (Artes Visuais) operaram com os conceitos desses lugares na proposição de suas pesquisas.

A primeira parte do texto se refere ao campo de História, explicitando como ele legitima esse estudo e tem como apoio as vozes de autores como Ana Maria de Oliveira Galvão e Eliane Marta Teixeira Lopes (2010), Peter Burke (2005), José D’Assunção Barros (2013), Carla Bassanezi Pinsky (2008) e Sandra Jatahy Pesavento (2003). A segunda parte do texto concerne ao levantamento e análise das fontes históricas - as dissertações de Mestrado em Artes Visuais. A última parte discorre sobre o campo da arte, este necessariamente indicado pelas fontes de pesquisa, sendo que o aporte teórico se situa em João Francisco Duarte Júnior

1 Desde 2018, a Linha 1 tem como título Educação em Artes e processos de formação estética. Como o estudo em questão tem caráter histórico e se refere a um período temporal, será mantido o título referente a esse período, no caso, o que está presente no corpo do texto. 


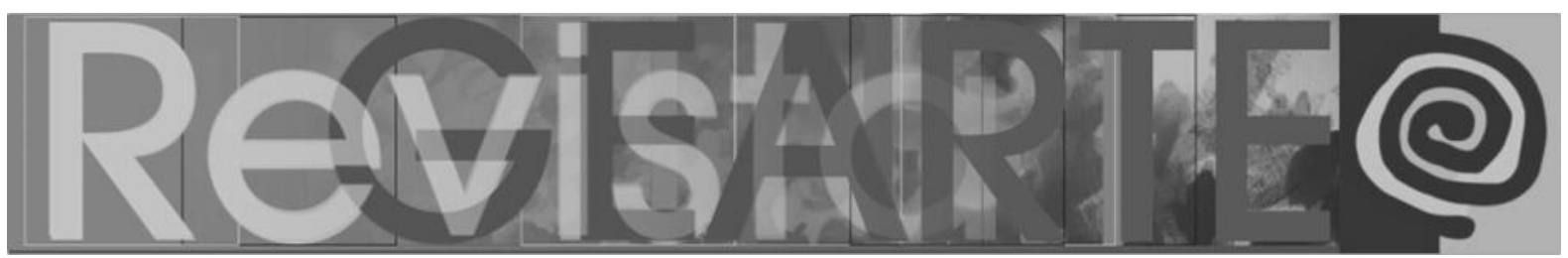

(2010), Jorge Larrosa (2015), Fernando Hernández (2007; 2011), Mirian Celeste Martins (2006) e Michel Maffesoli (2007).

\section{Como o campo da História ampara esse estudo}

A História da Educação é datada no final do século XIX, compreendida como uma disciplina de caráter utilitário desenvolvida nas "escolas normais", nos cursos de formação de professores. Nesse dado momento, o olhar era lançado em torno da história das ideias pedagógicas. No fim dos anos 1960, a produção da História da Educação deslocou-se para os programas de pós-graduação em educação, sendo que o fortalecimento da área se deu no fim dos anos 1980 por meio da fundação de associações de pesquisadores, como a ASPHE - Associação SulRio-Grandense de Pesquisadores em História da Educação (1996) e a SBHE Sociedade Brasileira de História de Educação (1998), de grupos de trabalho como a HISTEDBR - Grupo de Estudos e Pesquisas "História, Sociedade e Educação no Brasil" (1986) e de congressos como o Ische - International Standing Conference for the History of Educacion (1978).

$\mathrm{Na}$ atualidade, a História da Educação compreende uma abordagem científica ou uma prática historiográfica em que se pretende interpretar um recorte da realidade voltado aos fenômenos educativos do passado, incluído aqui a história do tempo presente, levando em consideração diferentes aspectos do contexto histórico analisado, econômicos, sociais, políticos, culturais, entre outros (GALVÃO; LOPES, 2010). A noção da história do tempo presente se situa em François Dosse (2012, p. 6), o qual, influenciado por Pierre Nora, considera que ela "reside na contemporaneidade do não contemporâneo, na espessura do 'espaço de experiência' e no presente do passado incorporado". Nesse sentido, o passado ao qual o objeto está inserido remete ao tempo vivido e incorporado pelo pesquisador. Para isso, faz-se o uso de novos objetos, abordagens e fontes em História da Educação. 


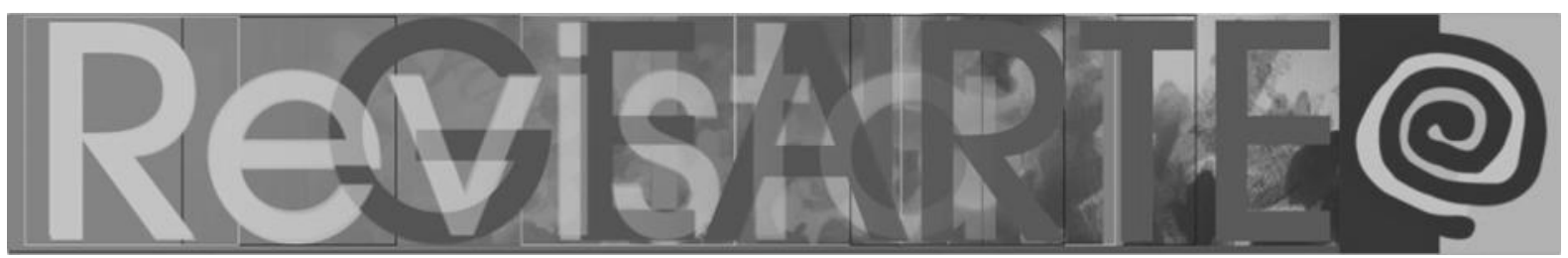

Tal mudança no discurso historiográfico se insere desde o movimento dos Annales, em que houve a proposição de novos objetos, novos problemas e novas questões para os estudos históricos. Ressalta-se que a Escola dos Annales surgiu nas primeiras décadas do século $X X$ e teve três gerações: a primeira geração foi liderada por Lucien Febvre e Marc Bloch (1929 - 1956), a segunda, por Fernand Braudel (1956 - 1968), e a terceira geração, por Jacques Le Goff e Pierre Nora (1969 - 1989). Aqui, o estudo é perpassado pelo viés da História Cultural, a qual surgiu na década de 1960 com a terceira geração da Escola dos Annales. A História Cultural é compreendida, de acordo com Burke (2008), como uma história escrita de forma multidisciplinar e interdisciplinar, tendo um discurso histórico analítico, subjetivo, interpretativo, interdisciplinar, científico, com tempo múltiplo, com expansão das fontes históricas, uma História-problema com novas e diferentes abordagens, objetos e possibilidades de investigação.

A História Cultural, portanto, apresenta noções de cultura intrínsecas a ela, sendo as noções de "linguagem", "representações" e de "práticas", o que desencadeia uma diversidade de objetos longe de serem considerados legítimos pela tradição histórica positivista. Salienta-se que o paradigma historiográfico do Positivismo foi inspirado inicialmente pelo pensamento de Augusto Comte, que estava em voga no século XIX até o início do século XX e, mais: o historiador sob o olhar desse paradigma, a partir da observação de documentos considerados oficiais, elencava os fatos do passado e os descrevia de forma linear, sem interpretá-los, construindo, portanto, um discurso com objetividade metodológica, neutra e com linguagem formalizada.

Avançando: os objetos da História Cultural remetem à cultura popular, à cultura letrada, à cultura material, às representações e às práticas discursivas. Há, do mesmo modo, interesse pelos sujeitos produtores e receptores de cultura, pelas agências de produção e difusão cultural, pelos meios através dos quais se produz e se transmite a cultura, como as práticas e os processos e, por fim, pelos padrões, as visões de mundo, as crenças e os sistemas simbólicos, entre outros (BARROS, 


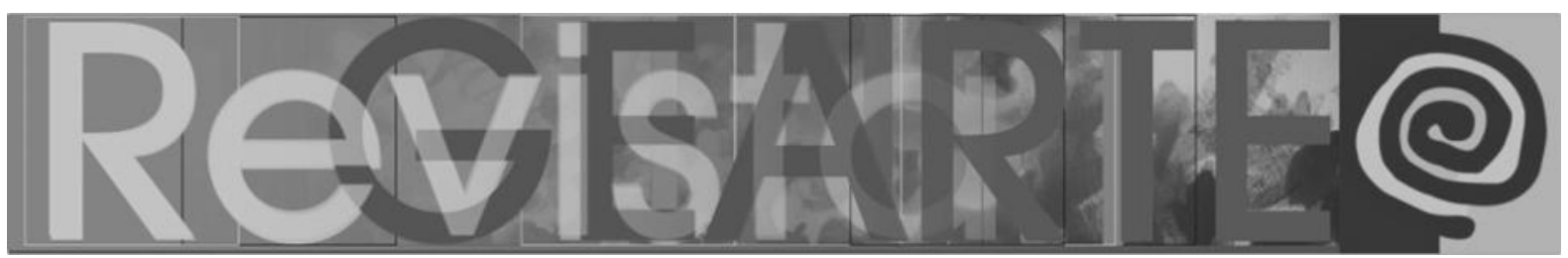

2013). Compreende-se, por tudo isso, a ampliação das investigações sob o viés da História Cultural.

Concernente às fontes históricas, todo documento produzido pelo homem, dito ou escrito, sobre qualquer temática que expressa suas ações, experiências, ideais (para além de temas voltados à política e à economia) torna-se relevante para a História Cultural. Essa ampliação de fontes disponível ao historiador para fazer História ficou conhecida como "revolução documental" (LE GOFF, 1995). Fontes documentais, arqueológicas, impressas, orais, biográficas, audiovisuais, sob a forma de documentos oficiais, processos criminais, registros policiais, certidão de nascimento, de casamento e de óbito, cartas, leis, documentos não oficiais, jornais, revistas, almanaques, documentos escolares, imagens, música, filmes, relatos, escritos de todos os tipos, entre tantas outras fontes são admissíveis em pesquisas históricas (PINSKY, 2008). Como observa Pesavento:

\begin{abstract}
[...] os exemplos são muitos, pois fontes são marcas do que se foi, são traços, cacos, fragmentos, registros, vestígios do passado que chegam até nós, revelados como documento pelas indagações trazidas pela História. Nessa medida, elas são fruto de uma renovada descoberta, pois só se tornam fontes quando contêm pistas de sentido para a solução de um enigma proposto (PESAVENTO, 2003, p. 98).
\end{abstract}

As fontes utilizadas pelo historiador podem ser de qualquer tipo e de qualquer suporte; elas dependerão das perguntas e dos sentidos atribuídos a elas para se constituírem fontes. Conforme foi indicado, as fontes são inúmeras, todas cabíveis. Entretanto, como fazê-las falar? E mais: quais são as fontes históricas desse estudo?

Nesse momento, retomo o tema deste artigo o qual tenta aproximar dois campos, o campo da Arte e o do Design. Tensionando a partir do campo da História, tem-se as práticas de pesquisadores utilizadas ou aplicadas ou pensadas para a sala de aula como preocupação teórico-metodológica. Ressalta-se que a abordagem teórico-metodológica da História Cultural legitima a realização desse estudo. Dessa forma, aponta-se como objeto de pesquisa a instituição que fomenta a pesquisa, a Universidade Federal de Pelotas (UFPel), especificamente o 


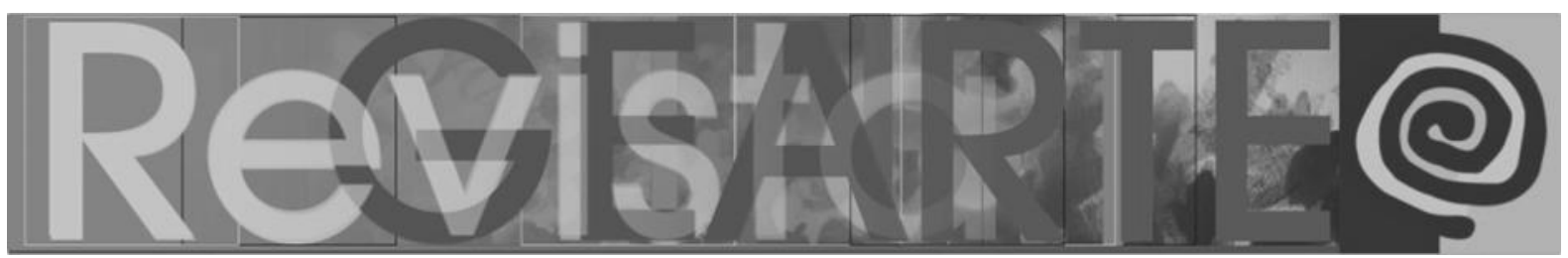

Programa de Pós-Graduação em Artes Visuais (PPGAV), e tem-se como fontes históricas as dissertações de Mestrado em Artes Visuais relativas às cinco primeiras turmas de mestres formados pela referida instituição de ensino.

Vale destacar que o PPGAV oferece formação na área de Artes Visuais por meio de duas linhas de pesquisa, sendo a Linha 1 intitulada Educação em Artes e processos de formação estética e a Linha 2, Processos de criação e poéticas do cotidiano. O seu objetivo é oferecer bagagem conceitual e experiências práticas que possibilitem aos pesquisadores e futuros profissionais "situar e interpretar social e historicamente as tendências que configuram as diferentes concepções sobre Artes Visuais na contemporaneidade e sobre os processos de formação nessa área" ${ }^{2}$. Os discentes do Programa advêm de diferentes áreas do conhecimento e não exclusivamente da área_das Artes Visuais. Os docentes também possuem essa característica, sendo a maioria com formação inicial em Artes Visuais.

Reafirmando a resposta à questão norteadora deste artigo: somos seres históricos e sem a passagem do tempo não haveria fontes para esse estudo. Sobre a nossa inserção no tempo, Aranha explica que:

[...] o presente não se esgota na ação que realiza, mas adquire sentido pelo passado e pelo futuro desejado. Pensar o passado, porém, não é um exercício de saudosismo, curiosidade ou erudição: o passado não está morto, porque nele se fundam as raízes do presente (ARANHA, 2012, p. 6).

Isso posto, e em busca de sentido, torna-se fundamental refletir sobre as proposições dos investigadores pertencentes ao PPGAV, para/com o campo do Design, proposições essas pertencentes a um passado recente, especificamente à História do Tempo Presente.

$\mathrm{Na}$ tentativa de aproximar os campos, são propostos os seguintes questionamentos: o que os pesquisadores do PPGAV desenvolveram de

2 Informação disponível em: <https://wp.ufpel.edu.br/mestradoartesvisuais/>. Acesso em: 30 jan. 2020. 


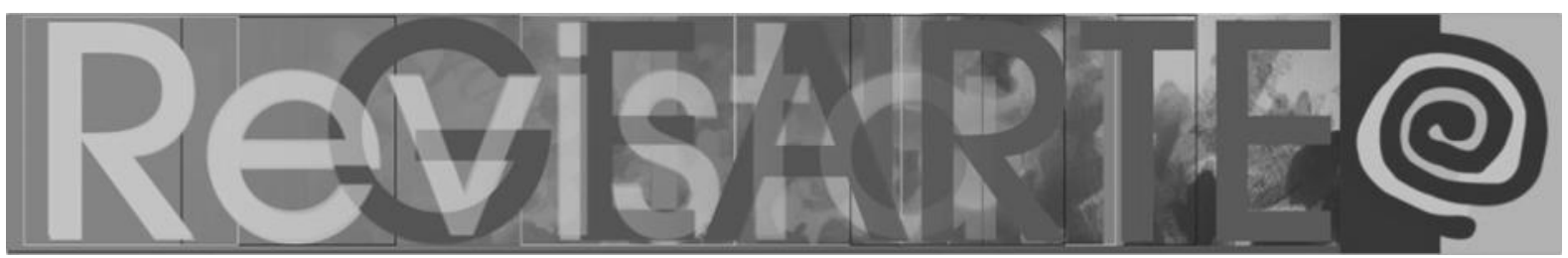

estratégias de ensino-aprendizagem na articulação dos campos em questão? O que foi apontado como desafio no espaço educacional do Design? Algo proposto foi compreendido como experiência pelos pesquisadores? Através desse mote serão apresentadas as fontes de pesquisa e a respectiva análise na tentativa de aproximar o Ensino da Arte e do Design, tendo a História como estratégia de pesquisa, a seguir.

\section{As pesquisas do PPGAV/UFPel: levantamento de dados e análise das fontes históricas (2012 - 2018)}

Considerando o campo da História, especificamente sob o viés da História Cultural, como estratégia para pensar acerca do Ensino da Arte e do Design, o primeiro passo teórico-metodológico foi o levantamento de dados. Essa etapa concerne às publicações de pesquisas de dissertações de Mestrado em Artes Visuais do PPGAV/UFPel de 2012 a 2018, referentes à primeira turma e à quinta turma de mestres do Programa. Tal recorte temporal foi realizado de acordo com as publicações de pesquisas disponíveis no site do referido Programa ${ }^{3}$. Nesse caso, dados como o número total de pesquisas por turma, o número total de pesquisas relacionadas ao campo do Design, a temática dessas pesquisas, a data em que as pesquisas foram concluídas, quem foram os pesquisadores, bem como os seus orientadores, foram investigados. De 76 pesquisas concluídas de 2012 a 2018, seis são relacionadas ao campo do Design. O Quadro 1 explicita os dados encontrados.

3 Disponível em: <https://wp.ufpel.edu.br/mestradoartesvisuais/publicacoes/dissertacoes/>. Acesso em: 30 jan. 2020. 


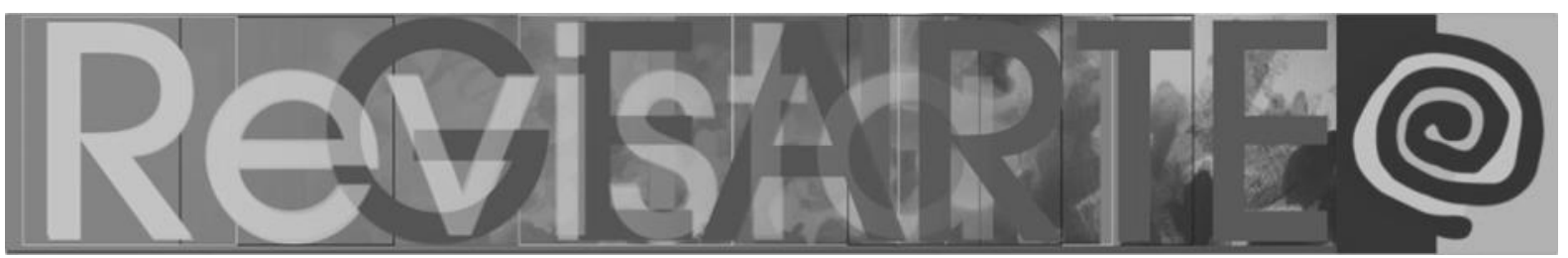

Quadro 1 - Pesquisas relacionadas ao campo do Design pertencentes ao Programa de Pós-Graduação em Artes Visuais (PPGAV/UFPel)

\begin{tabular}{|c|c|c|c|c|}
\hline $\begin{array}{l}\text { Nome do } \\
\text { pesquisador }\end{array}$ & Título da pesquisa & Orientador(a) & $\begin{array}{l}\text { Ano de } \\
\text { conclusão }\end{array}$ & Turma \\
\hline $\begin{array}{l}\text { Adriana Silva da } \\
\text { Silva }\end{array}$ & $\begin{array}{l}\text { O infográfico conceitual como } \\
\text { meio para desenvolvimento de } \\
\text { experiência significativa em web } \\
\text { arte. }\end{array}$ & $\begin{array}{l}\text { Lucia } \\
\text { Bergamaschi } \\
\text { Costa Weymar }\end{array}$ & 2014 & 1 \\
\hline $\begin{array}{l}\text { Mariana Leite de } \\
\text { Almeida }\end{array}$ & $\begin{array}{l}\text { GIFs: Educação estética, afeto e } \\
\text { ativismo através da imagem } \\
\text { animada. }\end{array}$ & $\begin{array}{l}\text { Lucia } \\
\text { Bergamaschi } \\
\text { Costa Weymar }\end{array}$ & 2015 & 2 \\
\hline $\begin{array}{l}\text { Lucas Pessoa } \\
\text { Pereira }\end{array}$ & $\begin{array}{l}\text { O Design de identidade visual } \\
\text { gráfica em produções } \\
\text { audiovisuais contemporâneas: } \\
\text { uma análise da apropriação da } \\
\text { visualidade medieval em O } \\
\text { Senhor dos Anéis, Game Of } \\
\text { Thrones e World of Warcraft. }\end{array}$ & $\begin{array}{l}\text { Lucia } \\
\text { Bergamaschi } \\
\text { Costa Weymar } \\
\text { Coorientadora: } \\
\text { Ana Paula Cruz } \\
\text { Penkala Dias }\end{array}$ & 2016 & 3 \\
\hline Paula Weber & $\begin{array}{l}\text { Livro das inquietações: } \\
\text { experiências singulares no } \\
\text { ensino do design. }\end{array}$ & $\begin{array}{l}\text { Lúcia } \\
\text { Bergamaschi } \\
\text { Costa Weymar }\end{array}$ & 2016 & 3 \\
\hline $\begin{array}{l}\text { Emerson Ferreira } \\
\text { da Silva }\end{array}$ & $\begin{array}{l}\text { O Espírito do Som: encontros } \\
\text { entre design, música e artes } \\
\text { visuais no projeto gráfico de } \\
\text { capas de disco. }\end{array}$ & $\begin{array}{l}\text { Lúcia } \\
\text { Bergamaschi } \\
\text { Costa Weymar }\end{array}$ & 2018 & 5 \\
\hline $\begin{array}{l}\text { Renan Humberto } \\
\text { Lunardello } \\
\text { Fonseca }\end{array}$ & $\begin{array}{l}\text { Arte, ecologia e design autoral: } \\
\text { um cartaz para o fim do mundo. }\end{array}$ & $\begin{array}{l}\text { Cláudio Tarouco } \\
\text { de Azevedo } \\
\text { Coorientadora: } \\
\text { Lúcia } \\
\text { Bergamaschi } \\
\text { Costa Weymar }\end{array}$ & 2018 & 5 \\
\hline
\end{tabular}

Fonte: Elaboração da autora.

De acordo com o Quadro 1, no primeiro momento, é possível verificar que não houve nenhuma pesquisa relacionada ao campo do Design na quarta turma do curso de Mestrado em Artes Visuais, entre 2015 e 2017, e que na turma de inauguração do curso houve somente uma pesquisa concluída. No segundo momento, constata-se que a professora Lúcia Bergamaschi Costa Weymar orientou o maior número de pesquisas, tendo apoio de orientação em apenas uma delas e sendo coorientadora na pesquisa conduzida pelo professor Cláudio 


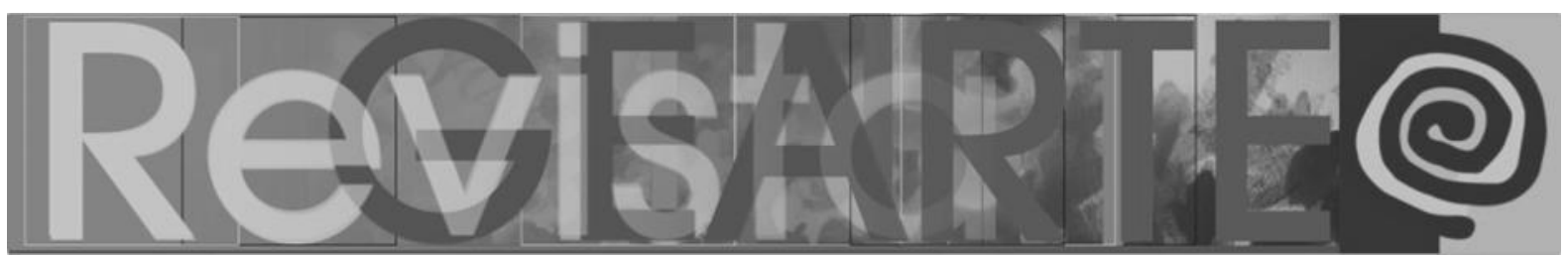

Tarouco de Azevedo. Isso é possível devido à sua atuação como professora nos cursos de Design Gráfico e Digital (UFPel) e como coordenadora de projetos de pesquisa, extensão e de ensino do campo. Além disso, ao analisar o corpo docente do Programa percebe-se que os seus pares demonstram interesses outros de pesquisa, como desenho, história em quadrinhos, livros de artista, objeto, deslocamento como arte, fotografia, gravura, dança, música, entre outros, e não propriamente design. A respeito dos pesquisadores, todos atuam no campo do Design e, exceto Adriana Silva da Silva, formada em Artes Visuais (Licenciatura) com especialização em Design, todos eles possuem graduação em Design ou em Artes Visuais com habilitação em Design.

É relevante destacar que as pesquisas consideradas para esse estudo são aquelas propostas para o Ensino do Design e que necessariamente se inserem na Linha 1 de estudo do PPGAV (que denominava-se Ensino da Arte e Educação Estética), a qual abarca estudos que tratam de processos educacionais em artes, relacionados a experiências estéticas e práticas pedagógicas, na educação formal e não formal; processos de mediação e formação em artes nas relações entre cotidiano, cultura e sociedade e ênfase na arte como campo de saber aberto, que envolve a historiografia da arte, teoria e crítica ${ }^{4}$. Nesse contexto, três pesquisas não serão consideradas para análise: $O$ Design de identidade visual gráfica em produções audiovisuais contemporâneas: uma análise da apropriação da visualidade medieval em O Senhor dos Anéis, Game Of Thrones e World of Warcraft, de Lucas Pessoa Pereira; O Espírito do Som: encontros entre design, música e artes visuais no projeto gráfico de capas de disco, de Emerson Ferreira da Silva; Arte, ecologia e design autoral: um cartaz para o fim do mundo, de Renan Humberto Lunardello Fonseca, pois pertencem à Linha 2 do curso.

No que corresponde às proposições das pesquisas analisadas, $O$ infográfico conceitual como meio para desenvolvimento de experiência significativa em web

4 Informação disponível em: <https://wp.ufpel.edu.br/mestradoartesvisuais/linhas-depesquisa/educacao-em-artes-e-processos-de-formacao-estetica/>. Acesso em: 27 fev. 2020.

CANSI, Lislaine Sirsi. O ensino das Artes Visuais e do Design: o campo da História como estratégia de pesquisa. 342 Revista GEARTE, Porto Alegre, v. 7, n. 2, p. 334-352, maio/ago. 2020.

Disponível em: http://seer.ufrgs.br/gearte 


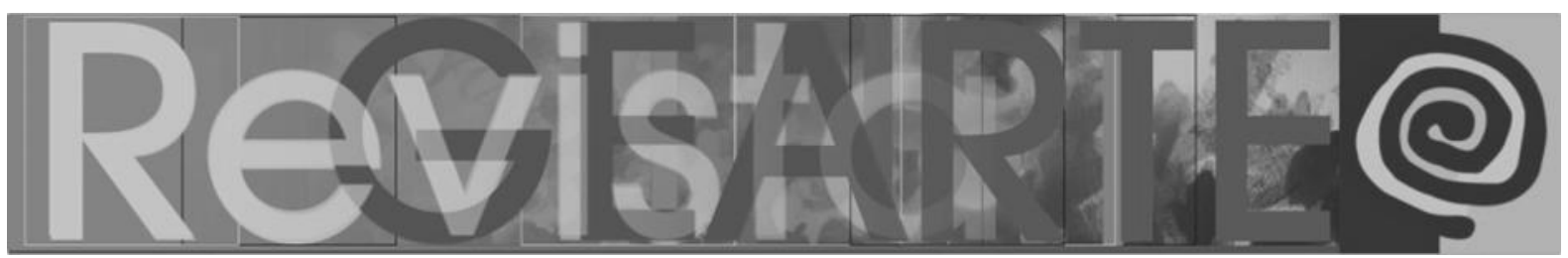

arte, de Adriana Silva da Silva (2014); GIFs: Educação estética, afeto e ativismo através da imagem animada, de Mariana Leite de Almeida (2015); Livro das inquietações: experiências singulares no ensino do design, de Paula Weber (2016), importa aqui realçá-las individualmente. Anterior a isso, é relevante salientar que Silva (2014) e Weber (2016) refletiram sobre o Ensino do Design advindo do pensamento do Ensino das Artes Visuais e se preocuparam com a prática, aplicando a proposta metodológica em sala de aula. Já Almeida (2015) refletiu sobre educação estética sem a aplicação de metodologias em sala de aula.

Adriana Silva da Silva (2014) relembra a sua experiência enquanto estudante do curso de Artes Visuais (UFPel), em que ministrou cursos de softwares gráficos, o que fez se apaixonar pelo campo do design. Em seguida, passou a se dedicar à docência e, naturalmente, pensar em sua prática pedagógica. É a partir de sua experiência como docente que surgiu o tema de sua dissertação, a relação entre arte e tecnologia perpassada pelo infográfico conceitual.

Diferente do mapa conceitual, que organiza e estrutura o conhecimento, Silva (2014, p. 15) entende que o infográfico "[...] é uma ferramenta do design que, ao associar imagens e textos, pode apresentar de forma clara e sintética um determinado conteúdo". Compreende-se que o infográfico conceitual foi sugerido como meio de experiência estética para os estudantes em que houve a aplicação da proposição da pesquisa, em uma turma de Ensino Médio do Instituto Federal Sul-Rio-Grandense em Pelotas (RS). A pesquisadora caracterizou o perfil do jovem de ensino médio, sujeito de sua pesquisa, a partir de suas relações com arte e tecnologia, bem como com aspectos estéticos (obra aberta, híbrida, trânsito, fluxo, experimentação remota, abandono do museu) e poéticos (ubiquidade, troca, imaterialidade, interação, atualização) da web arte.

Ao entender a preocupação da pesquisadora com a sua prática docente e, nesse contexto, com a aprendizagem significativa e não com a aprendizagem mecânica dos estudantes, verifica-se que a grande questão da pesquisa gira em torno da relação ensino-aprendizagem, especificamente a respeito das 


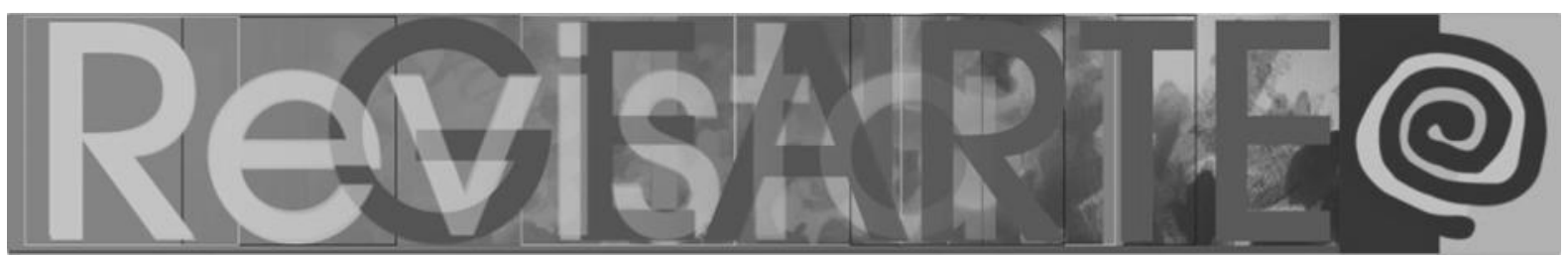

ferramentas utilizadas pelo docente, no caso, o infográfico conceitual, a partir da compreensão de teorias sobre educação estética e sensível e de aprendizagem significativa.

Mariana Leite de Almeida (2015) parte de si, do envolvimento que possui com as imagens virtuais da web desde a infância, especificamente as imagens compartilhadas nas redes virtuais de relacionamento, para pensar sobre o tema dissertado em sua pesquisa. Ela questiona os nossos relacionamentos na vida contemporânea a partir do mundo virtual, nossas vivências coletivas e o nosso papel no mundo (o nosso eu ativista ${ }^{5}$ ), sendo as imagens compartilhadas o elo de si com o outro.

Tais imagens, os GIFs (Graphics Interchange Format), representam o corpo social de quem os compartilha, estabelecem aproximações com o outro e refletem novas possibilidades de ser, além de modificar e/ou potencializar experiências estéticas. Almeida (2015), preocupada com o seu lugar no mundo, pensa que a construção de GIFs e o seu compartilhamento no mundo virtual (alimentado pelo coletivo) contribui para a multiplicação de si, de outros eus. Dessa forma, a construção do conhecimento é validada pelos laços de sociabilidade possibilitados pelo virtual e o GIF é proposto como possível ferramenta de ativismo virtual. Diz Mariana:

Como formato de imagem inserido na internet enquanto elo que favorece o laço social e como manifestação sensível e estética do cotidiano vivido (tal qual diversos outros elementos visuais contemporâneos), assume um papel imprescindível na construção do conhecimento cotidiano e, consequentemente, na educação estética natural da vivência social. (ALMEIDA, 2015, p. 13-14).

Percebe-se, portanto, que a questão de fundo da pesquisadora trata das relações entre afeto, educação estética e ativismo a partir da caracterização e da contextualização do GIF, elemento visual e animado recorrente na vida virtual da

5 De acordo com Almeida (2015, p. 41): "Ativismo é a busca a transformação da sociedade por meio da ação". 


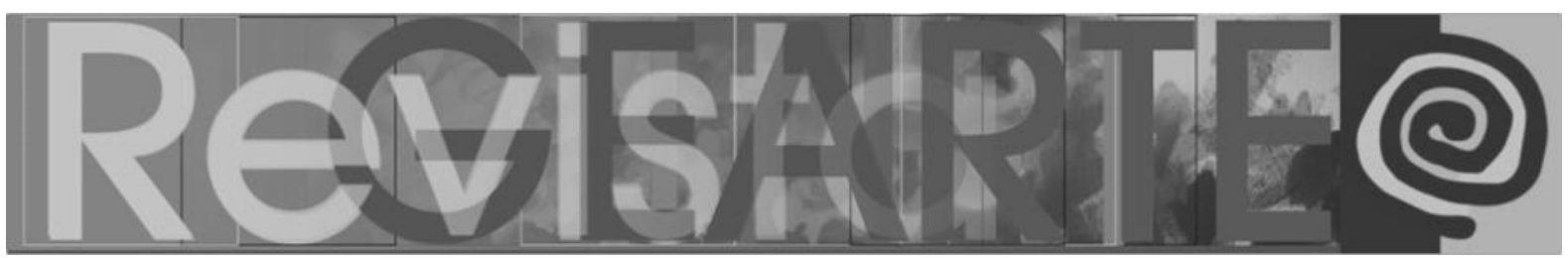

contemporaneidade. Para refletir sobre o GIF como possível ferramenta ativista, a pesquisadora, que é designer, idealizou e produziu os seus próprios GIFs ativistas, de acordo com os temas que mais a representa. É dessa maneira que Almeida, baseada em Duarte Jr., compreende a educação, no contato do sujeito com os sentidos que rodeiam a sua cultura.

Paula Weber (2016) também parte de si para realizar a sua pesquisa e é isso que intitula a sua dissertação: as suas inquietações frente ao apreço pelo mundo inteligível e a desvalorização do saber sensível na formação acadêmica, em especial, nos cursos de Design. Nota-se que a pesquisadora se posiciona na contramão da normativa comercial, em que o profissional de design executa o seu trabalho dotado de técnicas adequadas e carecendo de saberes estéticos e sensíveis.

Em sua pesquisa Weber (2016, p. 11) "objetiva construir uma estratégia teórico metodológica de abordagem qualitativa que considere as experiências singulares de alunos durante estágio docente na disciplina Identidade Visual do Curso de Design Digital da UFPEL". Para isso, a pesquisadora investigou tanto as narrativas educacionais naturalizadas quanto as questões da educação do sensível e das experiências singulares, debateu sobre o campo do design enquanto profissão neutra e/ou autoral, aplicou, a partir do estímulo de estudos da cultura visual, e analisou projetos de identidade visual desenvolvidos pelos discentes do quarto semestre do curso de Design Digital (UFPel), em 2015. Sobre tudo isso, a pesquisadora afirma que:

\footnotetext{
Acredito que mesmo sem a valorização de experiências singulares pode haver, sim, a criação de identidades visuais no design, mas não necessariamente estes trabalhos são carregados de estesia. Designs inestésicos obviamente podem ser qualificados e muitas vezes necessários, mas, apesar disso, a pesquisa "Livro das Inquietações" intenta demonstrar que experienciar projetos autoexpressivos e autoiniciados em cursos de formação na área que se conectem a experiências vividas favorece a formação de profissionais mais criativos e sensíveis. (WEBER, 2016, p. 116).
} 


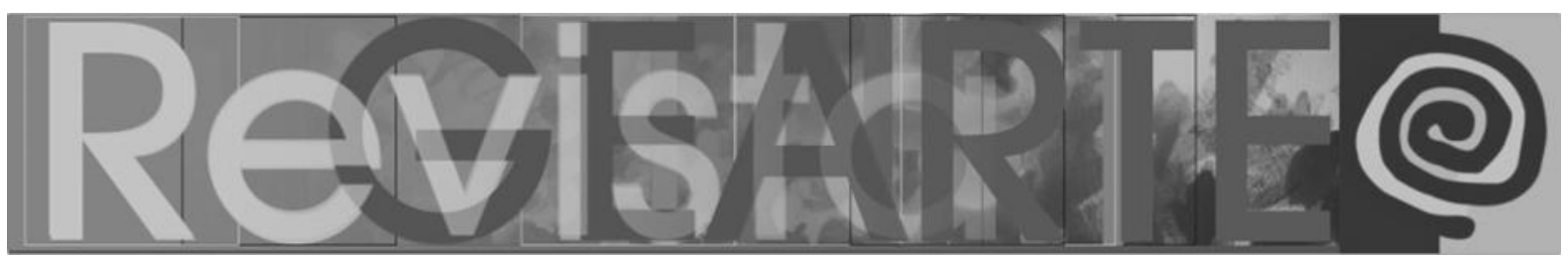

Compreende-se, portanto, que a pretensão teórica da pesquisadora foi metodológica. Diretamente ligada ao Ensino do Design, sugere que as experiências vividas pelos estudantes possam contribuir com uma criação em design autoral mais sensível e consciente.

\section{O campo da Arte e do Ensino vinculado às fontes históricas}

A educação através da Arte, do Ensino da Arte e da inclusão da Arte, particularmente da arte contemporânea, se encontra na contramão do imperialismo capitalista no mundo e no espaço educacional. Com a arte é possível pensar e criar o novo a partir das coisas de fora do sujeito, de suas afecções perante as circunstâncias acionadas pelas coisas do mundo. A Arte abarca olhares ao microscópico, valorizando detalhes da vida cotidiana. A Arte ocupa um lugar onde o oprimido pode encontrar espaços de resistência. O Ensino da Arte pode ser a potência contra a crise no mundo, contra o descontentamento político, contra a hipocrisia, contra a demagogia. O anestesiamento social se relativiza junto à "experiência" com a Arte. Tal "experiência" não concerne ao "saber da experiência" - relação entre conhecimento e vida humana. Diz respeito à concepção de "experiência" que implica em dar sentido ao que nos acontece (LARROSA, 2015). O artista abre espaço para a criação; o professor também. O professor é agente de formação de outros sujeitos; o artista também. O artista busca na dureza da vida cotidiana, detalhes conceituais para poder refletir e criar. Da mesma forma, o professor, o "professor catador" (HERNÁNDEZ, 2007), que busca na mesmice do cotidiano as inovações para o processo de ensino-aprendizagem (CANSI, 2016).

É a partir desse amontoado teórico que aqui se estabelece o vínculo com as fontes históricas. Esclareço: no texto $A$ cultura visual como um convite à deslocalização do olhar e ao reposicionamento do sujeito HERNÁNDEZ, 2011) compreende-se que fazer questões para as imagens que representam discursos pré-fixados permite a construção de outras narrativas e propiciam o reposicionamento do sujeito ante o mundo e o seu mundo. Assim se posicionaram as pesquisadoras das fontes históricas desse estudo. Mesmo tendo objetos de 


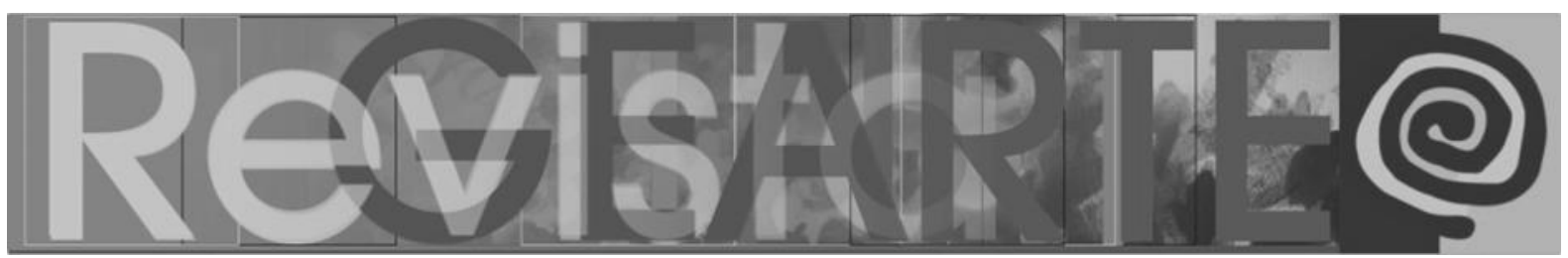

pesquisa diferentes, o interesse de Silva (2014), Almeida (2015) e Weber (2016) se manteve e se situa no âmbito da educação do sensível; esse é o ponto em comum nas pesquisas. É fundamental ensinar e aprender com suporte nos saberes sensíveis e na experiência, categorias conceituais advindas do Ensino das Artes Visuais e que obviamente condizem com o seu objeto, a arte, e o sistema ao qual ele está inserido, desde a sua produção no enfrentamento que o artista mantém em seu ateliê.

Em seu ateliê e, mais, em seu "pequeno território"6, o artista inventa suas próprias regras e assim cria, recria, observa e analisa criticamente, seguindo sua sensibilidade perceptiva. Nesse espaço-lugar, o artista, constituído pelo olhar desse sujeito que se faz estrangeiro (pois se distancia do próprio fazer e dos objetos estéticos que cria, a fim de perceber, nos interstícios, conceitos significativos para seu fazer poético), concebe e experiência, por meio da materialidade das coisas escolhidas por ele e das linguagens artísticas com as quais se envolve. Assim desenvolve seu pensamento em/sobre/com arte, enquanto segue se constituindo artista, num peculiar e individual processo criativo contínuo, ao longo de toda a sua vida. Pois, na contemporaneidade, o pensamento em/sobre/com arte, diretamente associado ao fazer poético, é absolutamente livre.

O professor de Arte, agente fundamental no sistema educacional é, de acordo com a concepção atual, o indivíduo que, nas práticas docentes, media conhecimentos em/sobre Arte. Freire (1983, p. 21) afirma que o professor "é alguém que, problematizando as questões que surgem, desafia o grupo a crescer na compreensão de seus próprios conflitos". Nesse sentido, a mediação em Arte implica em oportunizar possibilidades durante a prática pedagógica para que o estudante possa ter autonomia reflexiva e resolver questões no que tange às coisas do mundo e de seu mundo através da Arte.

6 Categoria desenvolvida no Curso Percursos, narrativas, descrições: mapas poéticos, ofertado pelo PPGAV - UFPel, sob a responsabilidade da professora Renata Azevedo Requião. 


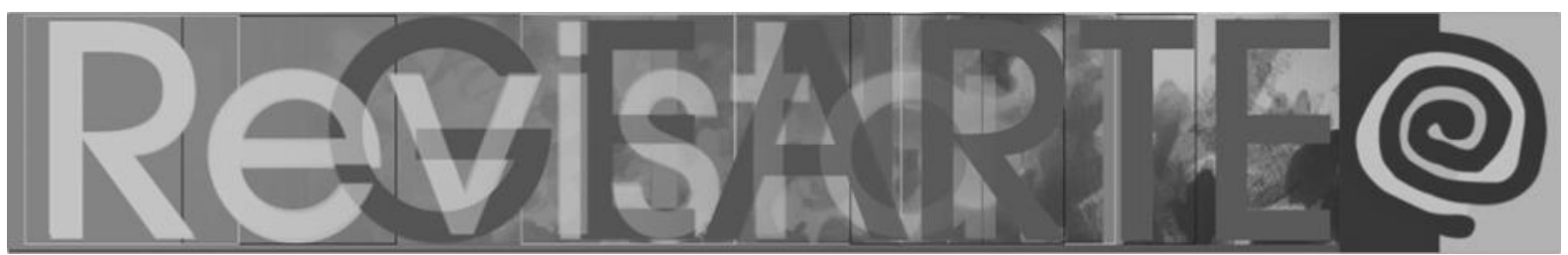

Martins (2006) questiona sobre quais alicerces profissionais ajudariam o professor a equilibrar-se entre os ovos que se colocam em seu caminho (fazendo uma analogia com a instalação Entrevidas, de 1981, da artista Anna Maria Maiolino) e usufruir a vida de educador. Responde que somente o professor inquieto seria capaz de driblar as mesmices do cotidiano educacional, já que suas características envolvem pesquisa, olhar indagador, criatividade sempre atenta às coisas do mundo, constante formação cultural e convivência e pesquisa com sua própria prática. Martins ressalta, ainda, a importância do educador em conviver com arte contemporânea para potencializar sua ação como professor propositor e sugere a inserção da experiência como algo provocativo para pensar a prática do professor juntamente com a processualidade de criação e as experiências de problematização advindas da arte. A autora afirma que:

\begin{abstract}
O artista apreende o sentido das qualidades com as quais trabalha e sabe tirar proveito delas. Educadores e aprendizes-educadores também podem perceber como a flexibilidade, a sutileza e tolerância pela ambiguidade são necessárias, ampliando conceitos, valorizando as subjetividades, as singularidades, a ludicidade e o humor, para lidar com o caos, com a insegurança com a tensão que também faz criar. Os artistas investigam de maneira qualitativa e é deles que como pesquisadores poderemos aprender a pesquisar, a dar forma ao que buscamos. (MARTINS, 2006, p. 5).
\end{abstract}

Para ampliar essa reflexão, é importante citar que:

\begin{abstract}
Alunos são aprendizes ativos e constroem significados individuais por meio da experiência, mas alguns significados comuns são construídos pelas crianças por meio da experiência coletiva da mídia. Nesse caso, o significado cultural pode não ser aquele o "preferido", mas antes o construído por um grupo que é parte de um público mais amplo. [...] Negligenciar a experiência do aluno fora da sala de aula é a resposta às representações conflitantes da arte. [...] O conhecimento que os alunos obtêm fora da sala de aula, por meio de formas populares de cultura visual, poderiam ser usados para dar-Ihes uma oportunidade de atentar para questões de representação e de conceitualização, criação e interpretação da arte. (FREEDMAN, 2010, p. 140-141).
\end{abstract}

Rememorando as proposições das pesquisadoras, a discussão apresentada faz sentido quando elas destacam inquietações ante a metodologias naturalizadas, refletem sobre a sua prática tendo foco a aprendizagem dos 


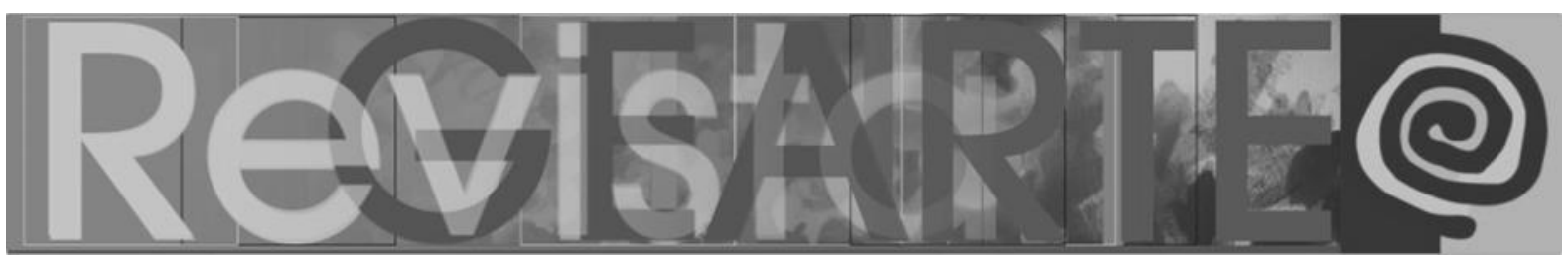

estudantes e consideram a cultura visual do estudante como tema a ser abordado em sala de aula.

Sobre experiência, é necessário salientar que:

Em todos os setores, é a experiência a palavra-chave para explicar a relação que cada um estabelece com o grupo, a natureza, a vida em geral. Experiência que ignora escrúpulos racionais, repousando essencialmente no aspecto nebuloso do afeto, da emoção, da sintonia com o outro. (MAFFESOLI, 2007, p. 203).

Por fim, no que concerne à "educação (do) sensível" no mundo contemporâneo, Duarte Júnior (2010, p. 26) reflete sobre a educação na contemporaneidade a partir de uma crítica à educação na modernidade em que fomos educados "para a obtenção do conhecimento inteligível (abstrato, genérico e cerebral) e deseducados no que tange ao saber sensível (concreto, particular e corporal)". Para o autor, atividades básicas da vida, automatizadas por nós, indicam a deseducação da sensibilidade. É necessário ter consciência que estamos "sem tempo", que estamos sendo engolidos por ele, que estamos "maquinizando" a vida e, portanto, não disponibilizando espaço para o saber sensível.

\section{Considerações finais}

A arte oferece lugar de pensamento de resistência, de experiência com o mundo, de ressignificações de experiências, e como objeto do Ensino da Arte entende-se essa proposição. A partir das pesquisas do Programa de PósGraduação em Artes Visuais (PPGAV) da Universidade Federal de Pelotas (UFPel), percebe-se haver um trânsito de saberes entre o que se tem pensado no campo do Ensino das Artes Visuais para o Ensino do Design. Sob a ótica das pesquisadoras Silva (2014), Almeida (2015) e Weber (2016) a preocupação ocorre no âmbito teórico-metodológico, especificamente no que diz respeito à experiência estética e à educação do sensível (já instituído no Ensino da Arte). 


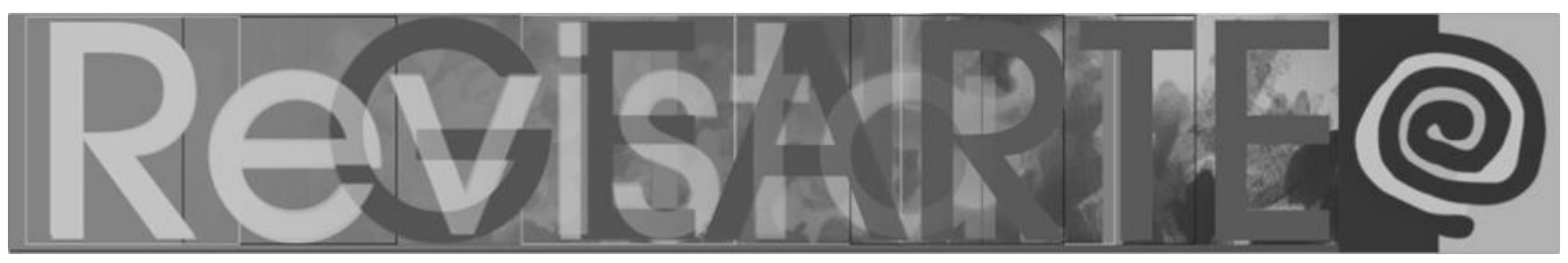

Silva (2014), desde a sua vivência como estudante de Arte e depois como docente, propõe refletir sobre ensino-aprendizagem. Destaca que ao professor de Design é imprescindível estar atento às coisas do mundo, às coisas da contemporaneidade, às coisas do público ao qual o professor atua e a essas coisas deve ser oferecido espaço de ensino em sala de aula na tentativa de buscar aprendizagem significativa. Entende-se, desse modo, a importância da inserção do infográfico conceitual em sala de aula naquele determinado espaço temporal.

Seguindo essa linha de raciocínio, para Almeida (2015), o Ensino do Design poderia ser pensado a partir das experiências estéticas que o discente temmantém-constroi com o mundo, assim como os GIFs, elementos visuais e animados indispensáveis para a sua vida social-virtual-ativista. Entende-se que "[...] é necessário que haja uma valorização das experiências ligadas aos interesses da sociedade como um todo" (ALMEIDA, 2015, p. 27) no Ensino do Design, isto é, a valorização das ações cotidianas, banais, as frivolidades, o coletivo e a educação para o sensível.

Por fim, Weber (2016) transformou as suas inquietações com a formação acadêmica e com profissionais do campo do Design em projetos de identidade. Dessa forma, a pesquisadora propôs e confirmou que é possível ter equilíbrio na idealização e no desenvolvimento de projetos unindo técnicas adequadas ao campo e saberes sensíveis e autorais.

Por fim, o campo da História, perpassado pela História da Educação sob o olhar da História Cultural, permitiu o fazer deste estudo teórico. Embora os dados levantados abranjam um número limitado de análise (apenas três pesquisas relacionadas ao campo do Design com ênfase ao Ensino), pois se trata de uma dada realidade histórica, é possível considerar que no Programa de PósGraduação em Artes Visuais da Universidade Federal de Pelotas, no período de 2012 a 2018, houve a sugestão de um ensino, advindo do Ensino das Artes Visuais, voltado ao estético e ao sensível para o campo do Design. 


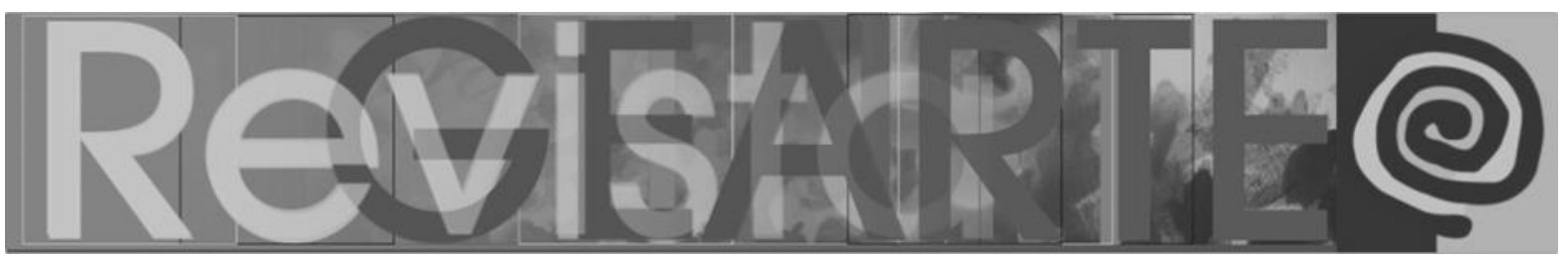

\section{Referências}

ALMEIDA, Mariana Leite de. GIFS: educação estética, afeto e ativismo através da imagem animada. 2015. 124 f. Dissertação (Mestrado em Artes Visuais) - Programa de Pós-Graduação em Artes Visuais, Centro de Artes, Universidade Federal de Pelotas, 2015.

ARANHA, Maria Lúcia de Arruda. História da Educação e da Pedagogia: geral e Brasil. São Paulo: Moderna, 2012.

BARROS, José D’Assunção. O campo da História: especialidades e abordagens. 9 ed. Petrópolis, RJ: Vozes, 2013.

BURKE, Peter. O que é História Cultural? RJ: Zahar, 2008.

CANSI, Lislaine Sirsi. Poética na docência [corpo e território]. 2016. 215 f. Dissertação (Mestrado em Artes Visuais) - Programa de Pós-Graduação em Artes Visuais, Centro de Artes, Universidade Federal de Pelotas, Pelotas, 2016.

DUARTE JÚNIOR, João-Francisco. A montanha e o videogame: escritos sobre educação. Campinas, SP: Papirus, 2010.

FREEDMAN, Kerry. Currículo dentro e fora da escola: representações da Arte na cultura visual. In: BARBOSA, Ana Mae. (Org.). Arte/Educação contemporânea: consonâncias internacionais. 3. ed. São Paulo: Cortez, 2010.

FREIRE, Madalena. A paixão de conhecer o mundo. São Paulo: Paz e Terra, 1983.

GALVÃO, Ana Maria de Oliveira; LOPES, Eliane Marta Teixeira. Território plural: a pesquisa em História da Educação. São Paulo: Ática, 2010.

HERNÁNDEZ, Fernando. A cultura visual como um convite à deslocalização do olhar e ao reposicionamento do sujeito. In: MARTINS, Raimundo; TOURINHO, Irene. (Orgs.). Educação da cultura visual: conceitos e contextos. Santa Maria: UFSM, 2011.

HERNÁNDEZ, Fernando. Catadores da Cultura Visual: transformando fragmentos em nova narrativa educacional. Porto Alegre: Mediação, 2007.

LE GOFF, Jacques. A História Nova. São Paulo: Martins Fontes, 1995.

LUNARDELLO FONSECA, Renan Humberto. Arte, Ecologia e Design Autoral: um cartaz para o fim do mundo. 2018. 80 f. Dissertação (Mestrado em Artes Visuais) - Programa de Pós-Graduação em Artes Visuais, Centro de Artes, Universidade Federal de Pelotas, Pelotas, 2018.

MAFFESOLI, Michel. O caminho da experiência. In: MAFFESOLI, Michel. O ritmo da vida: variações sobre o imaginário pós-moderno. Rio de Janeiro: Record, 2007.

MARTINS, Mirian Celeste. Entrevidas: caminhos inquietos de professores-propositores. educação, Santa Maria, v. 31, n. 2, p. 227-240, 2006. Disponível em: https://periodicos.ufsm.br/reveducacao/article/view/1540/852

PEREIRA, Lucas Pessoa. Design de identidade visual gráfica em produções audiovisuais contemporâneas: uma análise da apropriação da visualidade medieval em O Senhor dos Anéis, Game Of Thrones e World of Warcraft. 2016. 109 f. Dissertação (Mestrado em Artes Visuais) Programa de Pós-Graduação em Artes Visuais, Centro de Artes, Universidade Federal de Pelotas, Pelotas, 2016.

PESAVENTO, Sandra Jatahy. História \& História Cultural. Belo Horizonte: Autêntica, 2003.

PINSKY, Carla Bassanezi. (Org.). Fontes históricas. 2 ed. São Paulo: Contexto, 2008.

SILVA, Adriana Silva da. O infográfico conceitual como meio para o desenvolvimento de experiência estética significativa em web arte. 2014. 164 f. Dissertação (Mestrado em Artes Visuais) - Programa 


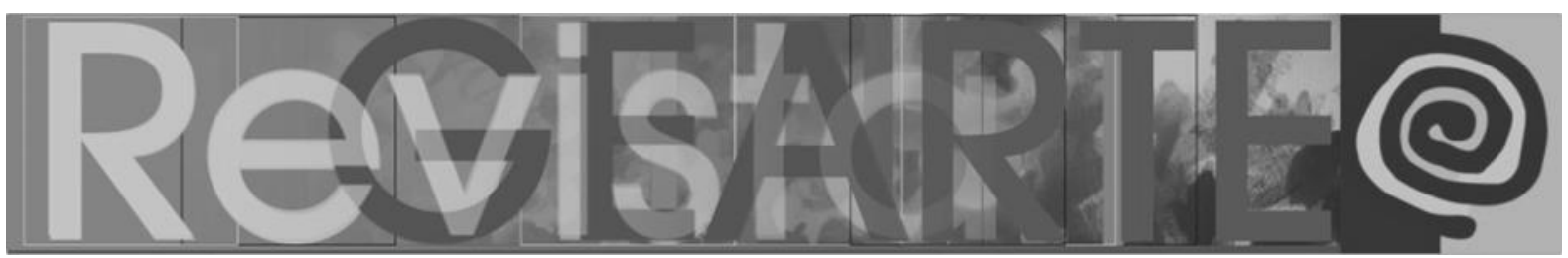

de Pós-Graduação em Artes Visuais, Centro de Artes, Universidade Federal de Pelotas, Pelotas, 2014.

SILVA, Emerson Ferreira da. O espírito do som: encontros entre design, música e artes visuais no projeto gráfico de capas de discos. 2018. Dissertação (Mestrado em Artes Visuais) - Programa de Pós-Graduação em Artes Visuais, Centro de Artes, Universidade Federal de Pelotas, Pelotas, 2018.

WEBER, Paula. Livro das inquietações: experiências singulares no ensino do design. 2016. $137 \mathrm{f}$. Dissertação (Mestrado em Artes Visuais) - Programa de Pós-Graduação em Artes Visuais, Centro de Artes, Universidade Federal de Pelotas, Pelotas, 2016.

\section{Lislaine Sirsi Cansi}

Possui graduação em Artes Visuais - Bacharelado e Licenciatura - pela Universidade Federal de Santa Maria (UFSM), especialização em Artes Visuais: Cultura e Criação pelo Serviço Nacional de Aprendizagem Comercial (SENAC/RS). Mestre em Artes Visuais, pela Universidade Federal de Pelotas (UFPel). Bolsista FAPERGS. Doutoranda em Educação, pela UFPel. Bolsista CAPES. É membro do Grupo de Pesquisa Centro de Estudos e Investigações em História da Educação (CEIHE). Tem experiência na área de Artes e Educação. Atuou como professora substituta do curso de Artes Visuais - Licenciatura, da UFPel; atuou como professora de arte no Colégio São José (Ensino Fundamental) e no Colégio Objetivo (Ensino Fundamental e Médio), em Pelotas, e nos Anos Finais do Ensino Fundamental nos municípios de Imbé, Capão da Canoa e Xangri-Lá (RS).

Orcid: http://orcid.org/0000-0001-8583-5290

E-mail: lislaine_c@yahoo.com.br

Currículo: http://lattes.cnpq.br/4351460434218577

Recebido em 29 de fevereiro de 2020 Aceito em 19 de maio de 2020 